\title{
Environmental Risk Evaluation of a Sanitary Landfill using Life Cycle Analysis Approach
}

\author{
Farah Ayuni Shafie ${ }^{1}$, Dasimah Omar¹, Subramaniam Karuppanan² \\ ${ }^{1}$ Faculty of Architecture, Planning and Surveying, ${ }^{2}$ Faculty of Health Sciences, \\ Universiti Teknologi MARA, Shah Alam, Selangor, Malaysia \\ farahayuni@salam.uitm.edu.my
}

\begin{abstract}
An Environmental Impact Assessment (EIA) auditing was carried out at a sanitary landfill in Kuala Langat, Selangor, Malaysia. It was conducted to assess the environmental and health impact of the landfill. The study also includes an environmental risk index and life cycle analysis (LCA) approach to evaluate the facility. The auditing arrives with a conclusion that this facility might pose a hazard to the environment and health if no adequate control measures are taken consistently. Environmental auditing and LCA simulation could become an essential tool in the monitoring of urban planning and development.
\end{abstract}

Keywords: urban planning, environmental health impacts, environmental management

eISSN 2514-751X @ 2018. The Authors. Published for AMER ABRA cE-Bs by e-International Publishing House, Ltd., UK. This is an open-access article under the CC BY-NC-ND license (http://creativecommons.org/licenses/bync-nd/4.0/). Peer-review under responsibility of AMER (Association of Malaysian Environment-Behaviour Researchers), ABRA (Association of Behavioural Researchers on Asians) and CE-Bs (Centre for EnvironmentBehaviour Studies), Faculty of Architecture, Planning \& Surveying, Universiti Teknologi MARA, Malaysia.

https://doi.org/10.21834/aje-bs.v3i8.282 


\subsection{Introduction}

It is increasingly difficult to ignore the fact that the world is undertaking the largest wave of urban growth the history has ever seen. It was reported that in 2008 , already more than $50 \%$ of the world's population was living in towns and cities. This number will expand to almost 5 billion by year 2030; with most of the urban growth converges in Africa and Asia (United Nations Population Fund, 2011).

In economic point of view, by creating more cities, more job opportunities are generated and ultimately higher economy level will follow. With good governance of the city, cities are expected to deliver education, health care and other day-to-day essential services more efficiently than less densely settled areas simply because of their advantages of scale and proximity. On the other side, however, thriving new townships will result in booming of basic infrastructure such as houses, transportation system, energy demand, food production and eventually the management of solid waste. The per capita solid waste generation rate in Malaysia varies from 0.45 to 1.44 kilogram per capita per day and is increasing year by year (Sakawi, 2011). Increase of waste generation over the years could be seen as the repercussion of expanding community.

Therefore, environmental health interest and concern in urban planning are significantly important for both town planners and environmental health professionals. The strong crossing point between urban planning and health that has been recognized for some time, thus required the concerted effort in introducing methods to assess environmental and health impact arising from an urban development. This paper would like to assess one important service in an urban development; waste disposal service using EIA auditing and LCA approach. The boundary of this study is within the operation in a landfill.

The EIA auditing study was conducted on a sanitary landfill in Kuala Langat, Selangor. A sanitary landfill is a site to safely isolate waste from the environment by means of burying, until the waste is completely degraded. This particular landfill is initially built to help resolve the need for secured landfill sites due to increasing waste generation within Selangor. The sanitary landfill will also redress the environment degradation problems related with indiscriminate solid waste disposal. All six phases of the landfill is planned for over of shelf life of 25 years and is now in its second year of operation. The landfill encompasses 160 acres of land and it receives approximately 1000 tonnes/day of municipal solid waste from Kuala Langat, Sepang and Putrajaya. The landfill operates six days a week from 0800 until 1800 hours with limited operating hours on Sundays and public holidays. Internal operating hours for daily soil cover shall extend to about 2000 hours. The operation within the landfill starts off with reception of waste, weighing of waste, unloading the waste into the cell, soil cover and finally leachate treatment.

\subsection{Environmental impact assessment auditing}

Environmental auditing is generally conducted to determine if the operation meets the regulatory requirement. Therefore, an environmental auditing was performed by monitoring various aspects of the environment; air quality, water quality, leachate toxicity, noise level and traffic impact assessment. Public survey was also performed on nearby neighbourhood 
to obtain the general feedback of the community towards the facility. An overall environmental health impact assessment is determined after looking into all the risks posed by the facility. Such assessment may also be used by the local authority, i.e city council, to direct the facility for closure, notice of improvement or necessary changes to the engineering control (Subramaniam et al, 2012).

\subsection{Environmental Risk Assessment}

After obtaining the environmental monitoring and public survey results, an overall environmental risk assessment can be conducted to evaluate the risk posed by the facility to the environment and health. For this study, Environmental Risk Index is determined using the software developed by Spain Civil Protection called CIRMA. Database EPISuite is used together with the CIRMA application to estimate the environmental risk. EPISuite database is to identify the characteristics of certain compounds that are available in the whole assessment boundary. The CIRMA computer application primarily works on four elements; source of risk, the primary control systems, transportation systems and vulnerable recipients. Figure 3 is the display of the end result from the computer application. Although the closest residential area is quite far from the facility, the health, safety and welfare of the workers and truck drivers within the facility is taken into consideration because they are the known "vulnerable recipients" in this study.

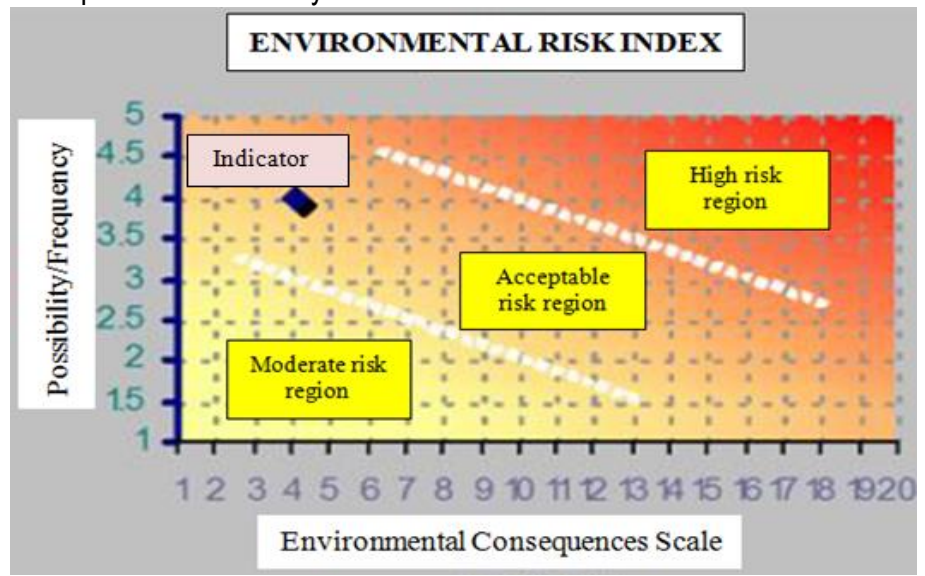

Fig. 3. End result display of CIRMA application for the facility

The outcome from the application can be used to determine whether the risk posed by the facility is within the acceptable region or certain mitigating measures shall be taken to reduce the risk. According to this subjective assessment, the environmental risk index of the facility is within the 'acceptable risk region'. This approach is also meaningful because the risk index is given in numeral form where one scenario can be compared with another. 
Environmental risk index of smaller tasks occurring in the landfill can be determined using the same approach, for instance, the process of unloading the waste and leachate treatment. From the outcome, more emphasis can be given to tasks with higher risk. Priorities in managing the arising risk can be appropriately justified. Continuous auditing and monitoring of the environmental risk of the facility is necessary to keep it from creating environmental and health risk. The longer the landfill operates, the more frequent environmental monitoring should be conducted. For the current phase of this landfill, an annual environmental monitoring is recommended to keep the risk lying low.

\subsection{DPSIR concept}

This paper would like to introduce the DPSIR concept to assist in planning of neighbourhood and township. The DPSIR concept is a causal framework for the analysis of interactions between society and the environment. It is based on the description of drivers, pressures, states, impacts and responses (DPSIR). The DPSIR framework has been developed from a tool to describe natural ecosystems under stress to a framework for describing human environment interactions and the related information flows.

\begin{tabular}{|cl|}
\hline 1. Driving Forces \\
- & Emerging \\
& population \\
- & Industry demand \\
- & Energy demand \\
- & Solid waste \\
& disposal \\
- & Sustainable \\
& development \\
& \\
\hline
\end{tabular}
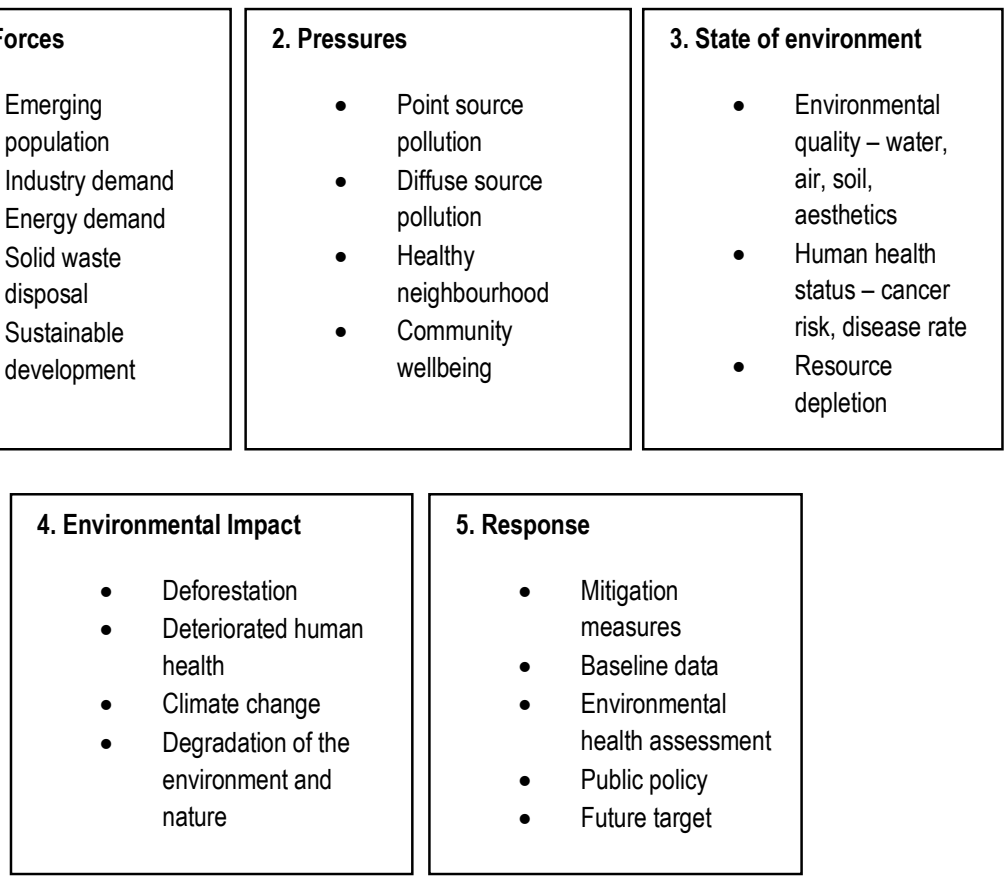

Fig.4. DPSIR concept in urban planning and development 
'Driving forces' bring about the requirement for the whole concept. In the rapid growth of urbanisation, basic amenities for a community become the need while not forgetting the importance of keeping up with sustainable development. Failing which, the needs could subdue the idea of sustaining the environment for future generation. Next, 'pressures' entail the scenario where there will be consequences to fulfill the need in the first place but also sees the expected good outcome. Subsequently, the current 'state' of the environment shall be looked into to expect whether the environment is able to withstand the necessary extraction from its account. Changes in the current state of environmental may affect the biosphere and its lives. Environmental 'impacts' are what to anticipate when the needs are being fulfilled, there might be resulting effects if no essential mitigating measures are being taken up. Finally, 'response' would come with current information available on the environment and future plants to facilitate accomplishing the need with preventive and curative action in place (Kristensen, 2004). The links seem to work in any way because of the dynamics of each component in solving the arisen issues.

DPSIR indicator model is applied as the best way to constitute information on the environment and look for causal relationships between the state of the environment, the main pressure and the responses (European Environment Agency, 2003). To depict the need of integrated environmental health assessment in the urban planning, Figure 4 described all the five components of the concept. Looking at the concept in a big picture may seem a complex task where the causal link between them can be interrelated. However, one may consider breaking up the concept into smaller assignment, for instance the pressure-state relationship. In this paper, most of the tasks are looking into the pressure-state relationship where the source of the problem is recognised and the current state of environment is monitored. In future research work, driving force-pressure relationship can be examined together with state of environment-response relationship to further investigate plan of action that could be implemented at earliest state possible in urban planning.

\subsection{Life Cycle Assessment}

A life cycle assessment (LCA) was conducted following the ISO 14040 (ISO, 2006). The LCA has 4 major steps: goal and scope, inventory analysis phase, impact assessment phase and an interpretation of the results phase. LCA is mostly used to compare the environmental performance between products. The best approach in conducting LCA is to have another element to be compared with but in this study, only a fraction of the waste in being introduced to the LCA just to have the general idea what are the impacts that might be posed by the content in the waste. The LCA was run on GaBi 4 using PE International and Ecoinvent 2.1 database. The general waste characterisation is used a guide to this interpretation of LCA. Figure 5 is the graphic demonstration of six impact categories that are looked into on the waste components. Plastics (in the form of polycarbonate) seem to be high in almost all the impact categories, followed by aluminium and cardboards. With this cross sectional analysis, a broad idea of what gives which impact can be seen. However, subjectivity in selecting the inputs to LCA also remains one of the biggest challenges in ensuring the output is compatible and significant with other studies. 


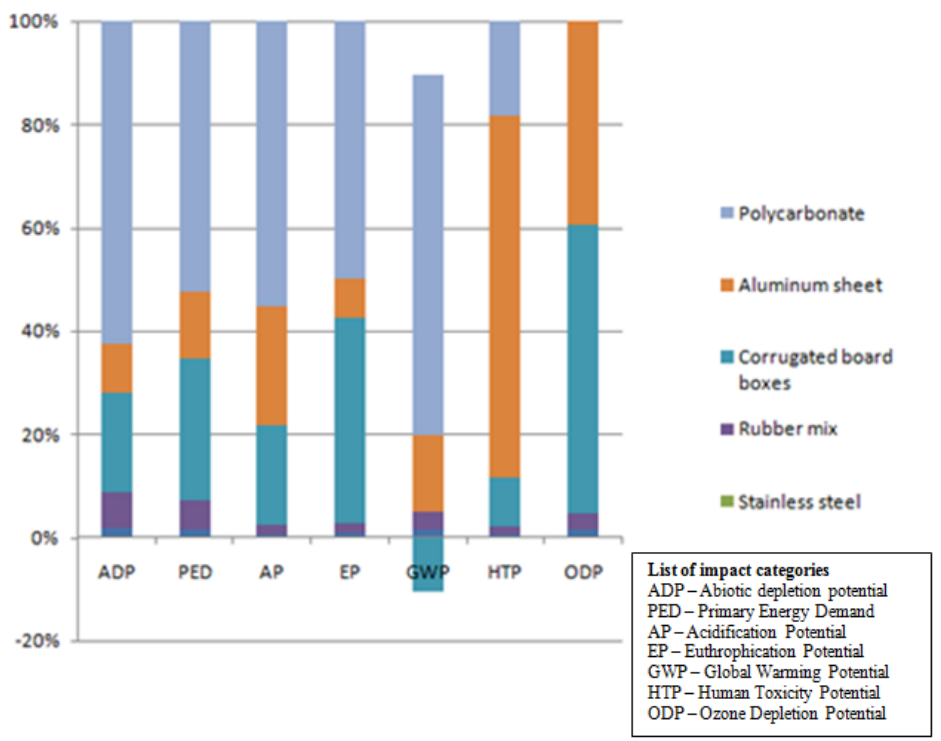

Fig. 5. Impact categories and waste substances using LCA approach

\subsection{Conclusion}

Urban planning for a healthy community includes a sound waste disposal system. Knowing various impacts a development can bring to the environment and human in particular, approaches have been taken and adopted among developed and developing countries. The Environmental Impact Assessment (EIA) has been widely accepted as a tool or to some extent an approach to identify how a proposed development or a project would affect the environment. In many developed and developing countries, EIA has been made mandatory and practiced legally to ensure expected outcome of a development is considered and mitigated before it takes place because apparently, land use and urban planning decisions affect environmental health even ones that might not seem specifically about health. The sitting and zoning of waste facilities such as sanitary landfill and incinerator is crucial due to the risk and hazard they may cause to the environment and health. Therefore, a combination of EIA and LCA might be able to identify and evaluate environmental and health impact of these facilities, providing sound judgement on the overall risk. This approach is also applicable to other spectrum of an urban planning such as a new township or an industrial area. With EIA and LCA and perhaps later with the introduction of multi criteria analysis, this approach could inform both urban planners and environmental health personnel in the earliest planning stage. Such approach shall be entrust at different stages of the planning process, providing meaningful feedback that can inform planning and design, as well as evaluation and mitigation. 


\section{Acknowledgements}

Authors would like to express gratitude to the other members of Environmental Impact Assessment auditing team - Noranrohaiza Abd Ghani, Farah Hazwani Mohd Zaini, Siti Nakiah Mat Ghani and Mohd Nor Farhan Basri for their assistance on the study. European Commission - Man, Health, Environment and Biodiversity in Asia (MAHEVA) programme is indebted for making the study feasible. Many thanks also go to Dr Xavier Gabarell of Chemical Engineering Department, Universitat Autonoma de Barcelona, Spain for his support.

\section{References}

Department of Environment Malaysia. 2007. Planning Guidelines for Noise Limits and Control.

ISO 14040 Environmental Management - Life Cycle Assessment - Principles and Framework (2006)

Kristensen, P. (2004). The DPSIR Framework, paper presented at Comprehensive / detailed assessment of the vulnerability of water resources to environmental change in Africa using river basin approach, UNEP Headquarters, Nairobi, Kenya, 27-29 September 2004.

Nazni, W. A, Luke, H., Wan Rozita, W.M., Abdullah, A.G., Sa'diyah, I., Azahari, A.H., Zamree, I., Tan S.B., Lee, H.L. \& Sofian, M.A. (2005). Determination of the flight range and dispersal of the house fly, Musca domestica (L.) using mark release recapture technique. Tropical Biomedicine (1):53-61.

Prasher, D., Morata, T., Campo, P., Fechter, L., Johnson, A.C., Lund, S.P., Pawlas, K., Starck, J., SliwinskaKowalska, M., Sulkowski, W. (2002). An European Commission research project on the effects of exposure to noise and industrial chemicals on hearing and balance. NoiseChem. 4 (14), 41-48.

Starr, K., Gabarrell, X., Villalba, G., Talens, L. \& Lombardi, L. (2012). Life Cycle Assessment of Biogas Upgrading Technologies. Waste Management, 32, 991-999

Sakawi, Z. (2011) Municipal Solid Waste Management In Malaysia: Solution For Sustainable Waste Management . Journal of Applied Sciences in Environmental Sanitation, 6 (1): 29-38.

Shafie, F., Omar, D., Subramaniam, K. \& Gabarrell, X. (2012). Environmental Health Impact Assessment and Urban Planning, paper presented at IFEH $12^{\text {th }}$ World Congress on Environmental Health, Vilnius, Lithuania, 22-27 May 2012.

Sisinno, C.L.S., Oliveira-Filho, E.C., Dufrayer, M.C., Moreira, J.C. \& Paumgartten, F.J.R. (2000). Toxicity Evaluation of a Municipal Dump Leachate Using Zebrafish Acute Tests Bull. Environ. Contam. Toxicol. 64: 107-113

Subramaniam, K. Ahmad Suhaimi, L.Z., Shafie, F., Ismail, R. (2012). Environmental Health Impact Assessment on Receptor Populations in a Municipality. World Congress of Risk 2012, Sydney, Australia, 6-8 Jun 2012.

United Nations Population Fund. (2011) The State of World Population 2011 : People and possibilities in a world of 7 billion. New York.

U.S. EPA (2010). Control Emmissions Technologies - Transport \& Dispersion of Air Pollutants, Washington.

U.S. EPA (2012). Mercury and Air Toxics Standards, Washington. 